\title{
Aneurysmal Bone Cyst of the Paranasal Sinuses: A Rare Entity
}

\author{
${ }^{1}$ Jagveer Singh Yadav, ${ }^{2}$ Ashok K Gupta, ${ }^{3}$ Nandita Kakkar \\ ${ }^{1}$ Senior Resident, Department of Otolaryngology and Head and Neck Surgery, Postgraduate Institute of \\ Medical Education and Research, Chandigarh, India \\ ${ }^{2}$ Professor and Head, Department of Otolaryngology and Head and Neck Surgery (Unit II), Postgraduate Institute of \\ Medical Education and Research, Chandigarh, India \\ ${ }^{3}$ Associate Professor, Department of Pathology, Postgraduate Institute of Medical Education and \\ Research, Chandigarh, India
}

Correspondence: Ashok K Gupta, Professor and Head, Department of Otolaryngology and Head and Neck Surgery (Unit II) Postgraduate Institute of Medical Education and Research, Chandigarh, India, Phone: +91-9814198850, e-mail: ashokpgi@ hotmail.com

\section{ABSTRACT}

Aneurysmal bone cysts are vascular tumors that cause expansion and erosion of bone. We present this rare entity involving maxillary, ethmoid and frontal sinuses along with orbit. Computed tomography and histopathology showed typical features of aneurysmal bone cyst. We discuss clinical, radiological and histological details along with endoscopic management and literature review. The rarity of tumor makes this case interesting for head and neck surgeons.

Keywords: Aneurysmal bone cyst, Paranasal sinuses, Endoscopic management.

\section{INTRODUCTION}

Aneurysmal bone cysts $(\mathrm{ABC})$ typically involve the long bones of the extremities, membranous bones of the thorax and pelvis, or vertebrae. The midline of the skull base is not the site of predilection for $\mathrm{ABC}$ and involvement of sinuses is extremely rare. There have been only five cases reports of involvement of sphenoid, ethmoid and maxillary sinuses. ${ }^{1-5}$ Skull and facial bone involvement accounts for 3 to $6 \%$ cases. $^{3,4}$ The mandible is the most common site in head and neck region. Aneurysmal bone cyst may be found with other benign bone lesions, such as nonossifying fibroma, giant cell granuloma, fibrous dysplasia and fibromyxoma. Although $\mathrm{ABC}$ is non-neoplastic condition, its potential for rapid growth, considerable destruction of bone, and extension into adjacent structures warrants early intervention. ${ }^{6}$ The rarity of this disease in head and neck region and involvement of adjacent structures makes this case more interesting for head and neck surgeons.

\section{CASE REPORT}

A 12-year-old boy came to the ENT services of Outpatient Department of Postgraduate Institute of Medical Education and Research with complaints of right sided nasal obstruction for 7 months, pain and bulging of right eye for 6 months. Nasal obstruction was gradually progressing, initially on right nostril and later on left side. History of mouth breathing was present. There was proptosis associated with intermittent nonpurulent watery discharge from both eyes. Vision was normal. There was no history of trauma or nasal bleeding.

The general and systemic examinations were normal. On anterior rhinoscopy, a reddish fleshy mass was seen in the right nasal cavity completely filling it. The surface of the mass was smooth, pinkish and it was firm but compressible. Sensation of touch was intact. The right nasal chamber revealed severe deviated nasal septum. Posterior rhinoscopy showed smooth bulge in nasophyrnx. There was obvious axial proptosis on right, the ocular movements were normal, and pupillary reaction and corneal sensation were intact. Fundus examination was normal. Routine blood, serum electrolytes, chest X-ray and urine analysis were normal.

Skiagram of paranasal sinuses showed a lesion of mixed radiodensity in the area of ethmoid and left maxillary antrum. Computed tomography of nose, orbit and sinuses showed that there was a well-defined expansile heterogeneous bony mass on right side of nasal cavity including anterior and posterior ethmoid, nasopharynx, maxillary antrum, frontal sinus. There was medial expansile shift of lateral nasal wall with proptosis of eye and nasal septum displaced to left side (Figs 1 and 2). Based on clinical and radiological findings, a provisional diagnosis of fibroosseous lession was made.

The patient was operated upon under general anesthesia through endoscopic approach. There was a bony hard mass 


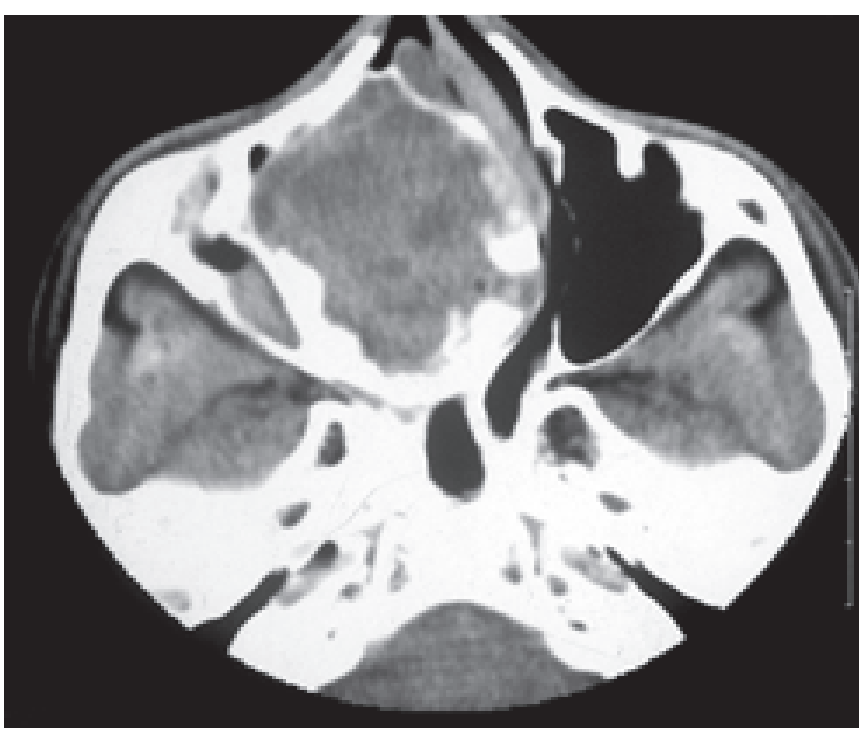

Fig. 1: CT scan axial view showing right maxillary sinus expansion

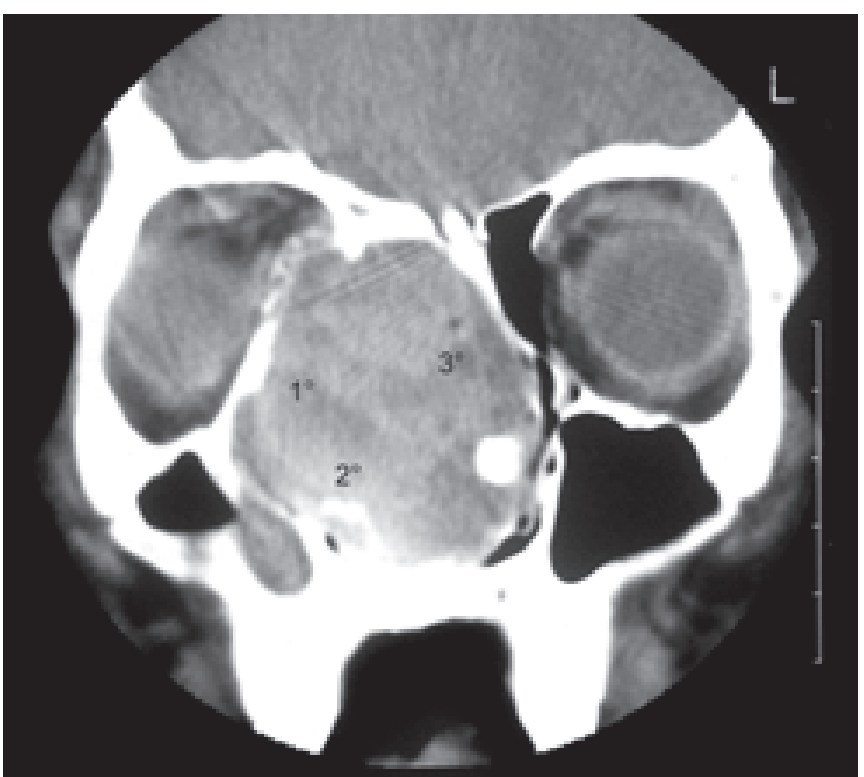

Fig. 2: Coronal section of CT scan showing mass in nasal cavity extending to maxilla, ethmoid and frontal sinuses with orbital involvement on right side

filling right nasal cavity, pushing middle turbinate, lamina pappyracea and nasal septum laterally up to choana, ethmoid, maxillary and floor of frontal sinus. Entire mass which was having bony hard shell and cystic areas in between was removed. Right side medicated nasal packing was done. The specimen removed was sent for histopathological examination. The patient had an uneventful postsurgical course. The pack was removed on 3 rd postoperative day and patient discharged on 4 th postoperative day.

Biopsy showed intact respiratory epithelium lining. There were cystic spaces devoid of any lining; cyst wall showed fibrosis and few multinucleate giant cells in surrounding tissue. The cyst cavity showed RBC at places. The adjacent areas showed fibrous lesion, which were ossifying at places, suggesting healing areas of aneurysmal bone cyst.

The histopathological examination revealed overall features of aneurysmal bone cyst (Fig. 3). The patient is being regularly followed up for last one year, postoperative $\mathrm{CT}$ and nasal endoscopic examination did not show any features of residual disease (Fig. 4).

\section{DISCUSSION}

$\mathrm{ABCs}$ are rare, vascular benign tumor-like lesions of bone, of unknown origin. They represent 1 to $2 \%$ of all primary tumors of the bone and occur most commonly in females under 20 years of age. In $70 \%$ of cases, it is located in metaphysis of long bones, only $2 \%$ are reported in head

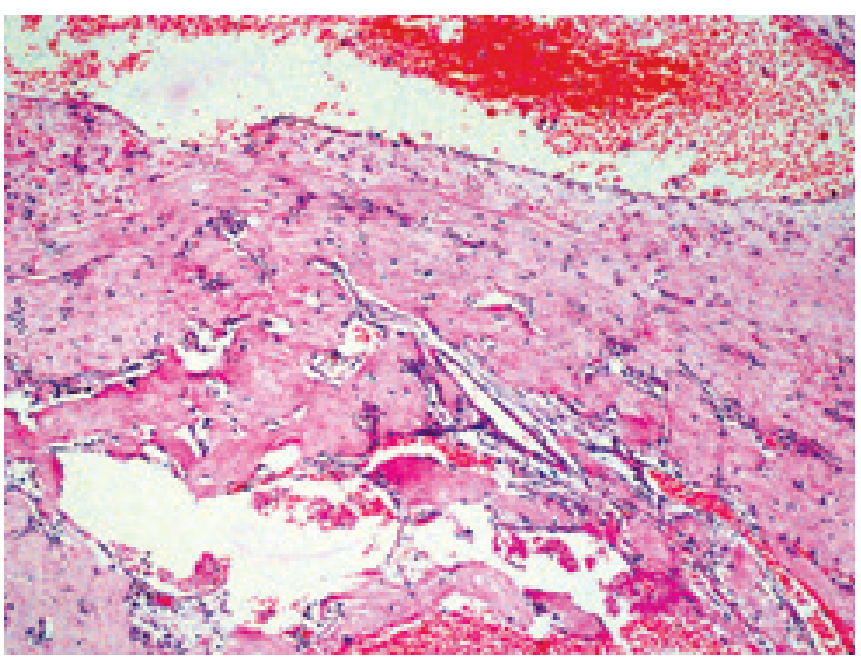

Fig. 3: Photomicrograph showing cystic spaces, RBCs and adjacent fibrosed areas ossification at places

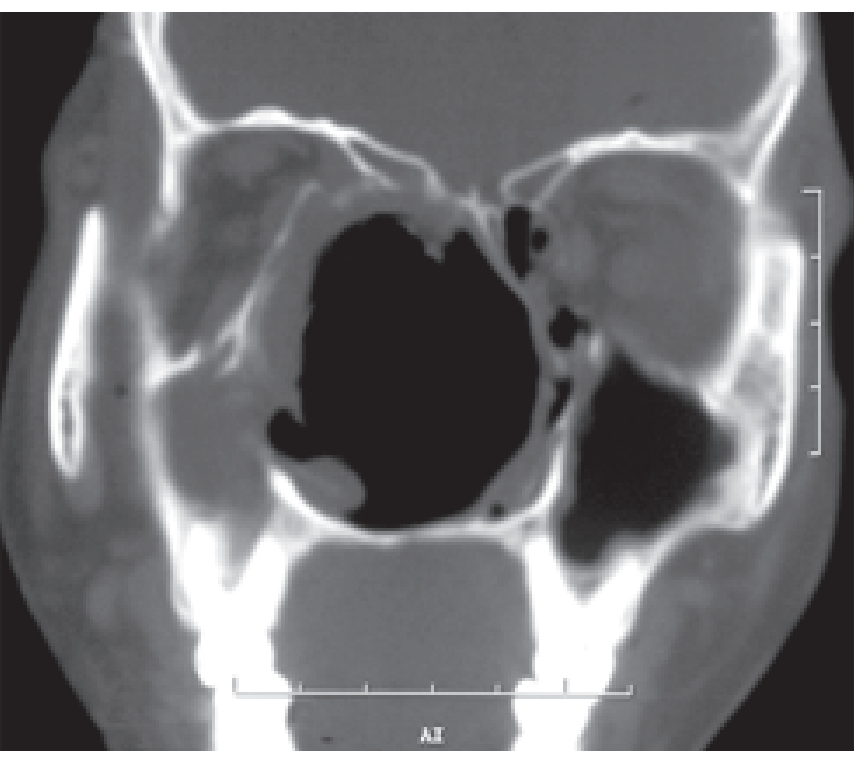

Fig. 4: CT scan (two weeks after surgery) 
and neck. ${ }^{3}$ Kaffe et $\mathrm{al}^{7}$ (1999) reported no difference in sex distribution, ratio of involvement of maxilla and mandible is $1: 2.4$, and $92 \%$ of lesions were in posterior part of jaw. ABC of PNS typically present with pressure symptoms, such as headache, nasal congestion, ${ }^{5}$ cranial nerve palsies, ${ }^{5,8,9}$ loss of vision ${ }^{8,9}$ and proptosis. ${ }^{5,8,9}$ The current view in the litrature is that cranial lessions constitute a separate entity, classified as primary or secondry depending on the presence or absence of an associated condition (giant cell tumors, chondroblastoma, fibrous dysplasia, etc.). ${ }^{10}$ Hady et al reported a case of aneurysmal bone cyst and claimed it to be the first reported case of aneurysmal bone cyst of maxilla. ${ }^{2}$ Radiological appearences can be diagnostic. The lesions are radiolucent in $87 \%$, radiopaque in $2 \%$ and of mixed opacity in $11 \%$. Plain skull radiographs are characterized by either a single or multiple blown-out lytic lesions. ${ }^{11} \mathrm{CT}$ usually reveals an expansion and thinning of overlying bone that may be multiloculated and might be confused with mucocele, but peripheral enhancement with iodide eliminates this possibility. ${ }^{12,13}$ MRI typically shows multiple fluid levels characteristic of $\mathrm{ABC}$, although not diagnostic (rarely occurs in giant cell tumors, fibrous dysplasia, simple bone cyst, chondroblastoma, telangiectatic osteosarcoma). ${ }^{14,15}$ Microscopic examination reveals bloodfilled channels bordered by a thin layer of spindle-shaped endothelial cells surrounded by connective tissue containing numerous multinucleated giant cells. Hemosiderin laden macrophages and new bone formation are found within the stromal matrix. ${ }^{15} \mathrm{ABC}$ most likely represents a degenerative process associated with other primary bone lesions. The presence of multiple giant cells may cause difficulty in differentiating the lesion histologically from osteoclastoma, fibrous dysplasia, ossifying hematoma and cavernous hemangioma of bone. The principal diagnostic error occurs if the histopathologist fails to appreciate the lining of the blood-filled spaces.

The $\mathrm{ABC}$ is a benign lesion of obscure pathogenesis, it grows rapidly with considerable destruction of bone and extension into adjacent tissue. Accepted treatment options include surgical excision, curettage, bone grafting, cryotherapy and radiotherapy. ${ }^{16}$
This is one of the rare $\mathrm{ABC}$ case reports, which was removed completely via endoscopic transnasal excision without any residual disease left behind.

\section{REFERENCES}

1. Kimmelman CP, Potsic WP, Schut L. Aneurysmal bone cyst of sphenoid sinus in child. Ann Otol Rhinol Laryngol 1982;91:339-41.

2. Hady MR, Ghanaam B, Hady MZ. Aneurysmal bone cyst of maxillary sinus. Journal of Laryngology and Otology 1990; 104:501-03.

3. Matt BH. Aneurysmal bone cyst of the maxilla: Case report and review of the literature. International Journal of Pediatric Otorhinolaryngology 1993;25:217-67.

4. Delorit GJ, Summers GW. Aneurysmal bone cyst of sphenoid sinus. Trans Am Acad Opthalmol Otolaryngol 1975;80:438-43.

5. Hunter JV, Yokoyama C, Moseley IF, Wright JE. Aneurysmal bone cyst of sphenoid with orbital involvement. Br J Opthalmol 1990;74:505-08.

6. Resnick D. Aneurysmal bone cyst. Diagnosis of bone and joint disorders (3rd ed). Philadelphia, PA: WB saunders 1995;6: 3866-78.

7. Kaffe I, Naor H, Calderons S, Buchner A. Radiological and clinical features of aneurysmal bone cyst of the jaws. Dentomaxillofacial Radiology 1999;28:167-72.

8. Yee RD, Cogan DG, Thorp TR. Optic nerve compression due to aneurysmal bone cyst. Arch Opthal 1977;95:2176-79.

9. Chartrand-Lefebvre C, Dubios J, Roy D, Raymond J. Direct intraoperative sclerotherapy of an aneurysmal bone cyst. AJNR May 1996;17:870-72.

10. Martinez V, Sissons HA. Aneurysmal bone cyst: A review of 123 cases. Cancer 1988;61:2291-304.

11. Kransdorf MJ, Sweet DE. Aneurysmal bone cyst: Concept, controversy, clinical presentation, and imaging. Am J Clin Pathol 1995;164:573-80.

12. Saito K, Fukuta K, Takahashi M, Seki V, Yoshida J. Benign fibrosseous lesions involving the skull base, paranasal sinuses and nasal cavity. Journal of Neurosurgery 1998;88:1116-19.

13. Calliauw L, Roels H, Caemaert J. Aneurysmal bone cyst in cranial vault and base of skull. Surg Neurol 1985;23:193-98.

14. Barnes L, Peel RL, Verbin RS, Goodman MA. Diseases of bones and joints. Surgical Pathology of Head and Neck. Newyork, NY 1985;2:883-1044.

15. Som PM, Schatz CJ, Flaum EG, Lanman TH. Aneurysmal bone cyst of paranasal sinuses associated with fibrous dysplasia. CT and MR findings. J Comput Assist Tomogr 1991;15:513-14.

16. Schreuder HBW, Veth RPH, Lemmens JAM, Koops HS, Molenar WM. Aneurysmal bone cysts treated by currettage, cryotherapy and bone grafting. J Bone Joint Surg (Br) 1997;79B:20-25. 